\title{
Time-varying price discovery in the eighteenth century: empirical evidence from the London and Amsterdam stock markets
}

Article

Accepted Version

Bell, A. R., Brooks, C. and Taylor, N. (2016) Time-varying price discovery in the eighteenth century: empirical evidence from the London and Amsterdam stock markets. Cliometrica Journal of Historical Economics and Econometric History, 10 (1). pp. 5-30. ISSN 1863-2505 doi: https://doi.org/10.1007/s11698014-0120-z Available at https://centaur.reading.ac.uk/38945/

It is advisable to refer to the publisher's version if you intend to cite from the work. See Guidance on citing.

Published version at: http://link.springer.com/article/10.1007/s11698-014-0120-z

To link to this article DOI: http://dx.doi.org/10.1007/s11698-014-0120-z

Publisher: Springer

All outputs in CentAUR are protected by Intellectual Property Rights law, including copyright law. Copyright and IPR is retained by the creators or other copyright holders. Terms and conditions for use of this material are defined in the End User Agreement. 


\section{CentAUR}

Central Archive at the University of Reading

Reading's research outputs online 
Noname manuscript No.

(will be inserted by the editor)

\title{
Time-varying price discovery in the eighteenth century: Empirical evidence from the London and Amsterdam stock markets
}

\author{
Adrian R. Bell • Chris Brooks · Nick Taylor
}

Received: date / Accepted: date

\begin{abstract}
This paper examines the time-varying nature of price discovery in eighteenth century cross-listed stocks. Specifically, we investigate how quickly news is reflected in prices for two of the great moneyed companies, the Bank of England and the East India Company, over the period 1723 to 1794. These British companies were cross-listed on the London and Amsterdam stock exchange and news between the capitals flowed mainly via the use of boats that transported mail. We examine in detail the historical context surrounding the defining events of the period, and use these as a guide to how the data should be analysed. We show that both trading venues contributed to price discovery, and although the London venue was more important for these stocks, its importance varies over time.
\end{abstract}

Key Words: Arbitrage, information shares, cross-listed stocks, historical finance, 18th century stocks.

JEL Classification Codes: N230, G140, C320

\section{Introduction}

There is a large and growing modern market microstructure literature on price discovery, defined as the process by and the speed with which new information is reflected in the prices of traded assets (see Lehmann, 2002, for a concise definition). It is sometimes the case that one security trades simultaneously on two or more markets, which is termed cross-listing, in particular with stocks. In such circumstances, it is of interest to determine how important each of the trading venues is in contributing to the movements in prices across these venues as a whole. In a particularly significant study, Hasbrouck (1995) proposes a method to examine the relative weight of each market's price discovery function in terms of the proportional contribution of that market's price changes to an overall underlying but unobservable price change common

Adrian R. Bell

ICMA Centre, Henley Business School, University of Reading

Chris Brooks

ICMA Centre, Henley Business School, University of Reading

Nick Taylor (corresponding author)

School of Economics, Finance and Management

University of Bristol

Bristol

BS8 1TN

United Kingdom

Tel.: +44 (0)117928 8606

E-mail: nick.taylor@bristol.ac.uk 
to all markets. ${ }^{1}$ Within this framework, price discovery measures are calculated using the parameters from a vector error correction (VEC) model applied to price changes in each market. ${ }^{2}$

Although sophisticated techniques for examining price discovery were not developed until very recently, it is of interest to consider whether markets during the eighteenth century were able to efficiently incorporate information and to investigate how news flowed from one market to another. We will analyse two stocks that were cross-listed on the London and Amsterdam stock exchanges over the period August 1723 to December 1794, namely the Bank of England (BOE) and the East India Company (EIC). Given that these were British companies, it is perhaps to be expected that the key direction of information flow on the underlying activities of the companies would be from London to Amsterdam. News relevant to the cross-listed stocks travelled from Britain to Holland twice per week via "mail packet boats," for which the British postal service held the monopoly. Koudijs (2013) argues that information may also have travelled in the opposite direction when news arose on the continent due to Amsterdam's closer physical proximity to it. Key information would have included success or failure in on-going warfare. News from battlefields on the European continent might reach Amsterdam first, for example. In addition, information from the East Indies may also have originated in Amsterdam if it was brought back from there on Dutch ships, although this happened rarely. Conversely, news from the North American continent would probably have reached London first. Indeed, Neal (1990, p. 163) argues that "information of great influence on the price of British stock reached England before it reached Amsterdam."

Cross-listing was very useful for these companies since it enabled them to increase the funding available at a key time in their development, and this was almost certainly the first example of cross-listing anywhere in the world. By the end of the seventeenth century, the Dutch had accumulated considerable sums of money that were available for investment. Wilson (1941) argues that demand from Amsterdam helped to support stock prices at times when it was lacking from England. These British companies were attractive to Dutch investors as they provided more potential growth opportunities than those available for their own domestic stocks. In the early 1700s, Dutch investors have been argued to have held up to a third of BOE's stock (Bowen, 1989), although over the century, interest gradually shifted towards the EIC so that by 1767, the Dutch owned $30 \%$ of the EIC.

While Dutch investors brought welcome resources, because of the potential for arbitrage and short-term speculative motives rather than long term investment, they later came to be blamed as a contributory factor in causing instability and excessive volatility of the share prices. The relatively softer legal regime in Amsterdam encouraged speculative activity to take place there preferentially (Neal, 1990).

To the authors' knowledge, the current study is one of only a handful of sophisticated econometric analyses of the stocks that were cross-listed in London and Amsterdam during the eighteenth century and the first to use cutting edge techniques from the market microstructure literature to investigate the relative amount of price discovery in the two centres. The approach that we implement allows for a time-varying estimation of the price discovery measures. Moreover, our bootstrap test allows us to test for variation within as well as across sub-periods. These results should help to shed new light on the relative role of Amsterdam, and whether in fact Dutch traders can be apportioned blame for the periodic collapses in prices that ensued.

The pioneering work on how integrated the Amsterdam and London markets were was conducted by Neal (1987). ${ }^{3}$ He shows that the corresponding price series across the two exchanges demonstrate very similar patterns and properties. He separates the overall period 1723-1794 into four distinct phases of peace and four phases of war, and into pre- and post-Barnard act sub-samples. ${ }^{4}$ For the BOE and EIC, the differences in the correlations of the price series across the two exchanges are very small. ${ }^{5}$ Neal (1987) also

\footnotetext{
1 Since its development, the information shares approach has been extended and successfully applied to cross-listed stocks (see, e.g., Huang, 2002, Pascual et al., 2006, Chan et al., 2007, and Hoag and Norman, 2013), government bonds (see, e.g., Campbell and Hendry, 2007, and Caporale and Girardi, 2013), derivatives (Booth et al., 1999, and Chakravarty et al., 2004), and the market for carbon emissions (Mizrach and Otsubo, 2014). The vast majority of previous studies assume that price discovery is time-invariant (see Aitken et al., 2012, and Hoag and Norman, 2013, for recent exceptions).

2 The use of the VEC model is common in the extant literature, and is consistent with a number of market microstructure models; see, e.g., section II in Hasbrouck (1995).

3 The only other contribution in this area is the study by Dempster et al. (2000). They examine the extent to which the two markets are integrated using a common features approach. To this end they implement a VEC model too, and proceed to test for common cycles rather than using the price discovery approach as we do. They find that the two markets were indeed highly interlinked, and that price movements across the two markets were matched in both the short and long runs. Dempster et al. argue that, "relevant movements in the market seem to have originated in London..."

4 This act forbade options and forwards being traded in London (Neal, 1990, p. 150).

5 The correlations between the corresponding first differences of prices vary slightly more over the sub-periods but since no formal tests of significance are conducted, it may be that they merely represent standard variations in correlation estimates that would occur over time even if the data generating process remained constant throughout.
} 
estimates autoregressive moving average (ARMA) models for the changes in prices, arguing that the smaller the optimal number of parameters in the fitted model, the more (weak form) efficient is the market. He finds that the optimal model order is almost always $(0,0)$ - implying that information was reflected quickly in price changes for both centres, which leads Neal to conclude that the markets were well integrated during the period as well as efficient. ${ }^{6}$ It is this central finding that we re-examine in our paper. Specifically, we highlight the informativeness of each market by quantifying a high level of market integration, and document significant time-variation in this quantity. In so doing we are able to demonstrate that rich information dynamics are not the preserve of modern financial markets, and that sophisticated modern techniques can be usefully employed to analyse historical problems.

The remainder of this paper is organised as follows. Section 2 describes the econometric approach that we use to model the movements in stock prices over time and to evaluate price discovery. Section 3 then describes the stock markets considered and Section 4 discusses the results. Finally, Section 5 offers some concluding comments.

\section{Price Dynamics and Price Discovery}

This section contains details of the model used to describe stock price changes and is followed by a description of the market efficiency (price discovery) measures used in the paper. A simplified version of the model (with numerical examples) is also provided to illustrate the key ideas.

\subsection{Price Discovery Measures}

We start by considering an existing model of returns used in the context of price discovery. The following VEC model assumes that price changes associated with cross-listed assets are a linear function of past price changes and past mispricing between the cross-listed asset prices:

$$
\Delta \mathbf{y}_{t}=\boldsymbol{\alpha} \boldsymbol{\beta}^{\prime} \mathbf{y}_{t-1}+\sum_{i=1}^{p} \boldsymbol{\Gamma}_{i} \Delta \mathbf{y}_{t-i}+\boldsymbol{\epsilon}_{t}, \quad t=1, \ldots, T,
$$

where $\mathbf{y}_{t}$ is an $(m \times 1)$ vector of jointly determined (logged) asset prices, $\boldsymbol{\alpha}$ and $\boldsymbol{\Gamma}_{i}$ are coefficient matrices of suitable dimension, $\boldsymbol{\beta}$ is an $(m \times 1)$ vector such that the mispricing series $x_{t}=\boldsymbol{\beta}^{\prime} \mathbf{y}_{t}$ is stationary, and $\boldsymbol{\epsilon}_{t}$ is an $(m \times 1)$ vector of error terms such that $\boldsymbol{\epsilon}_{t} \sim \operatorname{IN}(\mathbf{0}, \boldsymbol{\Sigma})$, with covariance matrix $\boldsymbol{\Sigma}=\left\{\sigma_{i j}, i, j=1, \ldots, m\right\} .^{7}$

To see how this model and its parameters are related to price discovery, we need to construct measures of the long run impact of a shock in one particular market on the other markets in which the stocks trade. To this end, it is possible to express (1) in terms of the following Stock and Watson (1988) common stochastic trend representation:

$$
\mathbf{y}_{t}=m_{t}+\nu_{t}
$$

where

$$
m_{t}=m_{t-1}+\mathbf{D}^{\prime} \boldsymbol{\epsilon}_{t}
$$

Here $\boldsymbol{\nu}_{t}$ is a suitably defined stationary error term, and $\mathbf{D}=f\left(\boldsymbol{\alpha}, \boldsymbol{\beta}, \boldsymbol{\Gamma}_{i}\right)$ is an $(m \times 1)$ vector calculated using a recursive formula with coefficients determined by the values of $\boldsymbol{\alpha}, \boldsymbol{\beta}$ and $\boldsymbol{\Gamma}_{i}$; see, e.g., Pesaran and Shin (1996) for an explicit expression. Within the context of cointegrated prices of equivalent assets traded in $m$ markets (e.g., cross-listed stocks), this common stochastic trend can be interpreted as the unobservable efficient price (Hasbrouck, 1995), with D measuring the contribution of each market to changes in the efficient price.

The above interpretation motives the component share measure introduced by Booth et al. (1999), Chu et al. (1999), and Harris et al. (2002). Specifically, they consider a standardised version of D such that the component share associated with the $j$ th market is given by

$$
\mathrm{CS}_{j}=\mathbf{D}^{\prime} \mathbf{e}_{j} / \sum_{j=1}^{m} \mathbf{D}^{\prime} \mathbf{e}_{j}
$$

6 This finding corroborated Neal's (1985) earlier finding that the London, Amsterdam, Paris and New York markets were well integrated in the nineteenth century, and the findings of Harrison (1998), who shows that the distribution of price changes existing at that time was very similar to that of today.

7 The intercept in (1) is suppressed for presentational purposes only. 
where $\mathbf{e}_{j}$ is an $(m \times 1)$ selection vector. As an alternative, Hasbrouck's (1995) information share measure associated with the $j$ th market (in which the squared variance-weighted relative values are considered) is given by

$$
\mathrm{IS}_{j}=\left(\mathbf{D}^{\prime} \mathbf{L} \mathbf{e}_{j}\right)^{2} / \sum_{j=1}^{m}\left(\mathbf{D}^{\prime} \mathbf{L} \mathbf{e}_{j}\right)^{2},
$$

where $\mathbf{L}$ is an $(m \times m)$ lower triangular matrix obtained via the Cholesky decomposition of $\boldsymbol{\Sigma}$ such that $\mathbf{L L}^{\prime}=\boldsymbol{\Sigma} .^{8}$

The parameters in (1) and the price discovery measures in (3a) and (3b) are linked via the parameter vector $\mathbf{D}$ (recall $\mathbf{D}=f\left(\boldsymbol{\alpha}, \boldsymbol{\beta}, \boldsymbol{\Gamma}_{i}\right)$ ). It follows that if the parameters in (1) vary over time then so do the price discovery measures. ${ }^{9}$ We investigate whether such variation exists in two ways. First, we follow Hoag and Norman (2013) and estimate (1) over pre-defined periods. Second, to avoid reliance on pre-specified breakpoints (that is, known sub-periods), we estimate (1) using a rolling window of data. In both cases, time-variation in the parameters in (1) is permitted (including the residual covariance matrix) that will ultimately deliver time-varying price discovery measures, denoted $\mathrm{CS}_{j, t}$ and $\mathrm{IS}_{j, t}{ }^{10}$

\subsection{Examples}

To further clarify the link between the VEC model parameters and price discovery measures consider the following scenario in which two markets exist, with the difference between the prices following a stationary series; that is, prices are cointegrated with the cointegrating vector $\boldsymbol{\beta}=[1,-1]^{\prime}$. Furthermore, we assume that all $\boldsymbol{\Gamma}_{i}$ equal zero. Under these assumptions, price changes are determined as follows:

$$
\begin{aligned}
& \Delta y_{1, t}=\alpha_{1}\left(y_{1, t-1}-y_{2, t-1}\right)+\epsilon_{1, t}, \\
& \Delta y_{2, t}=\alpha_{2}\left(y_{1, t-1}-y_{2, t-1}\right)+\epsilon_{2, t},
\end{aligned}
$$

where $\Delta y_{1, t}=y_{1, t}-y_{1, t-1}$ and $\Delta y_{2, t}=y_{2, t}-y_{2, t-1}$. In this instance, only the values of $\alpha_{1}$ and $\alpha_{2}$ determine D. To illustrate this relationship consider the following three numerical examples:

$$
\begin{aligned}
& \text { Example 1: } \boldsymbol{\alpha}=\left[\begin{array}{l}
\alpha_{1} \\
\alpha_{2}
\end{array}\right]=\left[\begin{array}{c}
0 \\
+1 / 2
\end{array}\right] \Rightarrow \mathbf{D}=\left[\begin{array}{l}
D_{1} \\
D_{2}
\end{array}\right]=\left[\begin{array}{l}
1 \\
0
\end{array}\right], \\
& \text { Example 2: } \boldsymbol{\alpha}=\left[\begin{array}{l}
\alpha_{1} \\
\alpha_{2}
\end{array}\right]=\left[\begin{array}{l}
-1 / 4 \\
+1 / 2
\end{array}\right] \Rightarrow \mathbf{D}=\left[\begin{array}{l}
D_{1} \\
D_{2}
\end{array}\right]=\left[\begin{array}{l}
2 / 3 \\
1 / 3
\end{array}\right], \\
& \text { Example 3: } \boldsymbol{\alpha}=\left[\begin{array}{l}
\alpha_{1} \\
\alpha_{2}
\end{array}\right]=\left[\begin{array}{l}
-1 / 2 \\
+1 / 2
\end{array}\right] \Rightarrow \mathbf{D}=\left[\begin{array}{l}
D_{1} \\
D_{2}
\end{array}\right]=\left[\begin{array}{l}
1 / 2 \\
1 / 2
\end{array}\right]
\end{aligned}
$$

In Example 1, prices in market 2 depend on past mispricing $\left(y_{1, t-1}-y_{2, t-1}\right)$, while prices in market 1 do not. In this instance, prices in market 1 are said to Granger-cause prices in market 2 in the long run. Moreover, in terms of price discovery (as given by D), only shocks to market 1 have an effect on the efficient price (see $(2 \mathrm{~b})$ ). In Example 2, both prices depend on past mispricing; however, the majority of price discovery will take place in market 1. Finally, in Example 3, shocks in both markets contribute equally to variation in the efficient price.

\section{The Application}

We consider an application of the above measures to one of the longest spans of cross-listed data available, viz. eighteenth century cross-listed stocks.

\footnotetext{
8 The use of the Cholesky decomposition means that the estimated measure is not invariant to the ordering of the data (Lütkepohl, 1991). To avoid this dependence we augment the original information share measure by replacing $\mathbf{D}^{\prime} \mathbf{L}$ with $\mathbf{D}^{\prime} \Sigma / \sqrt{\sigma_{j j}}$; see Pesaran and Shin (1998) for motivation within the context of impulse response functions.

9 Time variation in the residual covariance matrix associated with (1) will also affect the information share measure via L.

10 The residual covariance matrix is recalculated after each estimation of the model
} 


\subsection{The Markets}

Whilst Eighteenth century stock exchanges in London and Amsterdam were technically far removed from modern stock markets, they had similar features that support the current study. For instance, Neal (1990, p. 120) argues that "the evaluations of the equity of each joint-stock company made by investors trading and speculating in their shares on the stock exchanges of London and Amsterdam were much the same as the evaluations of corporate enterprises that are seen in modern stock markets."

Rather than being concentrated on one trading floor (either electronic or physical), Dale (2004, pp. 26-39) colourfully describes how the London Stock Exchange was focused in one particular precinct in the City of London, but with business being conducted in a variety of coffee houses in and around Exchange Alley. Thus the trading was not central and settlement was required to be done in person at the premises of each company. The market was given liquidity by "stockjobbers," "acting as principals, taking stock into their own books and quoting both a buying and selling price" (Dale, 2004, p. 27). Also, stocks could be purchased in a variety of ways including arrangements similar to today's contracts for spot purchase, forward purchase, call options, put options, and repos.

Both the Amsterdam and London exchanges also had a number of differences from modern stock exchanges. For instance, an absence of both institutional investors and of a financial regulator are obvious key distinctions that may affect the way that the markets function and the extent to which prices efficiently reflect information. Moreover, the transfer of information from one market to another occurs over a longer time frame. Physical delivery of information via mail packet boats means that price adjustments based on previous disequilibria (mispricing) will take place with a delay of several days. Given the relatively small amount of information delivered in this way, these adjustments are likely to be spread over a longer period of time than observed in contemporary markets.

Despite these differences, as we will show below, the main features of the price movements are very similar to those that might be expected from current markets (albeit with dynamics that evolve over a longer time frame), and thus the financial markets can operate effectively in the absence of electronic communications and a rigid regulatory framework.

\subsection{Data}

We consider the prices of two stocks cross-listed on the London and Amsterdam stock exchanges over the period August 1723 to December 1794, viz. BOE and EIC stocks. These are the largest of the "great moneyed companies," so called because they financed the reorganisation of the national debt in the eighteenth century by holding significant amounts of government debt securities (see Shea, 2000). ${ }^{11}$ These data are sampled on an approximately bi-weekly basis. ${ }^{12}$ We obtained the data for both the London and Amsterdam prices from the Inter-university Consortium for Political and Social Research (ICPSR) data depository. ${ }^{13}$ We also make use of annual dividend data obtained from Gary Shea (see Shea, 2000).

The original source of the stock data is "the Course of the Exchange," which is a printed list of the prices of stocks traded in London together with a number of exchange rates and the prices of several commodities. The list was made by John Castaing, a stock broker, and was printed twice per week from 1698, eventually becoming the price list of the London stock exchange. The data for the British stocks on the Amsterdam market were originally obtained from the Amsterdamsche Courant, a Dutch newspaper, but this information was only transcribed every two weeks by van Dillen (1931) for the period 1723-1794, which limits the length and frequency of analysis that can be conducted on the cross-listed stocks.

While it is clear that the securities traded in London were stocks, it is less certain what was the precise status of those traded in Amsterdam. An Act of Parliament, Barnard's Act, was passed in 1733 and sought to ban trading in futures, although it is not clear that the Act was successful, and trading in Amsterdam

\footnotetext{
11 While the original data source contains price data for the South Sea company as well as the BOE and EIC, we do not use this series since it is very thinly traded after the bubble of 1720 and so is likely to lead to inaccurate results. There were around 150 companies that were publicly quoted at some point between 1690 and 1834 (see Shea, 2000), but most of these were extremely small and with very incomplete records making them not amenable to formal statistical analysis.

12 The data frequency is known to be irregular (see Table 3 in Neal, 1987). However, it should be noted that the information share measure we employ is robust to situations in which the sampling frequency used does not coincide with the true frequency over which the data are generated (see Table 5 in Yan and Zivot, 2010).

13 See https://www.icpsr.umich.edu/icpsrweb/ICPSR/studies. The title of the archive is: Course of the Exchange, London, 1698-1823 and Amsterdamsche Beurs, Amsterdam, 1723-1794 (ICPSR 1008).
} 
appeared to continue largely as before. ${ }^{14}$ Van Dillen (1931) suggests that the time-series from 1723 to 1794 may comprise a mixture of both spot and time (forward) prices, with Neal (1990) arguing that prices were on average no higher in Amsterdam and no more volatile, which further complicates the issue of precisely what type of security the Dutch assets were. However, the most recent evidence suggests that reported Amsterdam prices were spot prices prior to 1747 and time prices thereafter (Beach et al., 2013).

As Neal (1990) notes, whether the Amsterdam securities were stocks or futures may have adverse effects on the quality of the mispricing series. We follow this warning and consider two implications of this observation concerning the mispricing series: it may have seasonal dynamics and may deviate from zero for prolonged periods (as implied by the cost-of-carry model of time prices). To address this issue, we pre-filter the data for seasonality (complicated by dividend effects) and stochastic trend effects, via a state-space model that includes a set of suitably defined exogenous variables. In doing this we can account for variation in the mispricing series due to unobservable maturity effects associated with the use of cross-listed spot and time prices.

Historically, while the markets appeared to function regardless, this was a period of considerable turmoil as a result of a series of wars and financial crises. A detailed examination of these events will help to put the statistical results in the following sections into context. Simply put, in terms of British involvement in warfare, the first major conflict was the War of Austrian Succession (1739-48), in which Britain was later allied with the Dutch republic and Austria against France, Prussia and Spain. The theatre of war involved conflict with France in North America and India. In the Seven Years War (1754-1763), Britain made large gains in North America from both France and Spain and also wrestled dominance over India from France. During this period of warfare, the Dutch were able to remain neutral, whilst Britain was now allied with Prussia. The major gains in North America were largely undone by the American War of Independence (1775-1783), where the American colonists, with support from France, were able to defeat the British following a long conflict, although Britain was able to retain control over Canada. Finally, this revolutionary fervour spread to France, which later embroiled Britain in the French Revolutionary wars spanning the final four years of the study (1790-1794). Closer to home, the Jacobin revolt of 1745 , led by the young pretender to the British throne "Bonnie Prince Charlie," caused an associated financial panic. The Jacobin forces were able to invade from Scotland and penetrate as far as Derbyshire, before retreating and being defeated at Culloden in April 1746. Despite all of this conflict, it is of note that the London market remained open to foreign investors throughout the period of study and therefore Amsterdam residents were continually able to trade.

Figure 1 presents plots of the prices and returns to BOE and EIC stocks. If we consider the price series first, it is evident that there are some fairly long swings lasting perhaps a decade at a time. The BOE price rose from around $£ 90$ in 1763 to almost double that value by May 1769, followed by a decade-long bear market. Another steep price rise occurred from the late 1770 s, with the price peaking at around £190 in 1792 , but then half this gain was lost by the end of the sample period. For the EIC, there is no real upward drift in prices. There was a rise of over $100 \%$ from the lowest value of $£ 117$ in May 1762 to around $£ 280$ by April 1769. But almost the entire increase was wiped out in the early 1770 s.

\section{Insert Figure 1 here}

Turning now to the returns time-series in the lower panels of the figure, the volatility clustering that is almost universally a feature of modern asset returns series is clearly evident, once again indicating that this early market demonstrates features that would be expected in contemporary finance. For both stocks, the period after the late 1770 s shows a particularly high variability compared to the relatively calm markets enjoyed in the $1750 \mathrm{~s}$, for example. It is also clear that the EIC was the considerably more volatile of the stocks, tying in with its reputation for being involved in inherently riskier businesses.

\subsection{Hypotheses}

It is generally accepted that the bulk of the relevant information flowed from London to Amsterdam (Koudijs, 2013). Consequently, one would expect the majority of price discovery to take place in London. To evaluate this conjecture we test the following null hypothesis:

\section{$H_{0}^{1}$ : The London component/information share equals 1/2,}

\footnotetext{
14 Indeed, as we show in the subsequent analysis, the proportion of price discovery attributable to Amsterdam rose slightly rather than falling.
} 
against the alternative that it does not equal $1 / 2$. This hypothesis is henceforth referred to as hypothesis 1 .

It is possible that price discovery may vary over time. For instance, it is quite possible that during the specific periods of war described above, relevant information from a battlefield on the European continent may reach Amsterdam before it reaches London. In this instance, we would expect Amsterdam to be the dominant market during such periods. Alternatively, institutional effects such as the imposition of the Barnard Act (or the accession of a particular Monarch) may affect the dominance of the London market during the sample period. Thus, the second null that we consider is the following:

\section{$H_{0}^{2}$ : The London component/information share equals 1/2 during all periods,}

against the alternative that it does not equal $1 / 2$ during all periods. This hypothesis is henceforth referred to as hypothesis 2 .

\subsection{Testing Methodology}

The above null hypotheses are tested by constructing bootstrap confidence intervals. To account for the heteroscedastic structure of the data underlying the price discovery measures, we make use of the wild bootstrap procedure proposed by Mammen (1993) - see Appendix A for a description of the bootstrap procedure used. Following completion of the wild bootstrap procedure, we construct basic bootstrap confidence interval limits; see Davison and Hinkley (1997) for further details. The lower and upper confidence limits associated with a $(1-\rho)$ confidence level are respectively given by

$$
\begin{aligned}
L_{j} & =\widehat{M}_{j}-\left(Q\left(\widetilde{M}_{j}, 1-\rho / 2\right)-\widehat{M}_{j}\right), \\
U_{j} & =\widehat{M}_{j}-\left(Q\left(\widetilde{M}_{j}, \rho / 2\right)-\widehat{M}_{j}\right),
\end{aligned}
$$

where $\widehat{M}_{j}$ is the estimated time-invariant price discovery measure (component or information share) associated with the $j$ th market, and $Q\left(\widetilde{M}_{j}, 1-\rho / 2\right)$ is the quantile function applied to the bootstrap estimates $\widetilde{M}$ at level $1-\rho / 2$.

When the rolling window approach is adopted, time-varying information and component shares are plotted over time such that a visual assessment can be undertaken. To subject this assessment to statistical inference we plot the excess time-varying price discovery measure $\left(\widehat{M}_{j, t}-1 / 2\right)$ against the $2.5 \%$ and $97.5 \%$ confidence interval limits.

\section{Results}

In this section we describe the results associated with the model used to adjust mispricing for institutional effects, the VEC model, and the price discovery measures.

\subsection{Adjusting Mispricing}

We consider the case where (log) prices in Amsterdam and London are cointegrated with the cointegrating vector $\boldsymbol{\beta}=[1,-1]^{\prime}$ imposed. ${ }^{15}$ Consequently, the difference between the Amsterdam and London prices represents the mispricing series in the VEC model. However, prior to estimation of the VEC model, the mispricing series must be adjusted for two institutional effects documented by Beach et al. (2013). These primarily relate to the fact that reported prices in Amsterdam were spot prices prior to 1747 and time prices thereafter.

First, the effect of dividends on prices occurs in London around the ex-dividend date, but affects Amsterdam prices around 30 days later. This will manifest itself in a higher mispricing between these dates. To adjust for this effect we add back the dividends to prices after the London and Amsterdam exdividend dates, with the timing of the latter established via visual inspection of the data. Second, prices in Amsterdam are subject to the effect of the "rescounter" settlement dates of February 15, May 15, August 15, and November 15. To control for this we perform a regression of mispricing on a variable that measures

\footnotetext{
15 Dempster et al. (2000), who also employ a VEC model, show that each of the London stocks has a [1 - 1] cointegrating relationship with its Amsterdam counterpart and so this specification is well founded.
} 
the number of days to the nearest settlement date (henceforth the mispricing model), and take the residual as our measure of adjusted mispricing. Moreover, as this effect is related to reported Amsterdam prices being time prices then it follows that these effects should be different after 1747. To allow for this change a dummy variable that interacts with the settlement date variable is included in the mispricing model. We finesse the adjustment of mispricing by incorporating an additional feature within the mispricing model. Specifically, 'other' long run deviations between Amsterdam and London prices are permitted by allowing the intercept in the mispricing model to follow a highly persistent process (that is, a random walk).

To incorporate all of the above effects we make use of a state-space representation of mispricing. Specifically, the following respective mean and intercept equations are assumed:

$$
\begin{array}{ll}
x_{t}=\tau_{t}+\theta_{1} \mathrm{SET}_{t}+\theta_{2} \mathrm{SET}_{t} \times \mathrm{D} 47_{t}+\eta_{1, t}, & \eta_{1, t} \sim \operatorname{IN}(0, G), \\
\tau_{t}=\gamma_{0}+\gamma_{1} \tau_{t-1}+\eta_{2, t}, & \eta_{2, t} \sim \operatorname{IN}(0, H),
\end{array}
$$

where $x_{t}$ is the difference between (logged) Amsterdam and London prices (after dividend effects have been removed), $\mathrm{SET}_{t}$ is the time (in days) to the nearest rescounter settlement date, $\mathrm{D} 47_{t}$ is a dummy variable that equals unity for all periods after 1746 (and zero otherwise), $\tau_{t}$ represents an unobserved stochastic intercept, and $\eta_{1, t}$ and $\eta_{2, t}$ are suitably defined error terms. In the subsequent analysis, the residual $\widehat{\eta}_{1, t}$ is used as the measure of adjusted mispricing.

Six specifications of the above model are considered. The first specification (denoted S1A) assumes no variation in the intercept equation and no determinants in the mean equation. The second specification (denoted S1B) again assumes no intercept variation, but allows settlement effects. The third specification (denoted S1C) assumes no intercept variation, but allows the settlement effects to change around 1747. The fourth, fifth and sixth specifications (denoted S2A, S2B and S2C, respectively) are the same as S1A, $\mathrm{S} 1 \mathrm{~B}$ and S1C except the intercept now follows a random walk (referred to as a stochastic trend). These specifications are achieved by imposing the following restrictions on (5a) and (5b):

$$
\begin{aligned}
& \text { S1A: } \theta_{1}=\theta_{2}=0, \gamma_{1}=0, H=0, \\
& \text { S1B: } \theta_{2}=0, \gamma_{1}=0, H=0, \\
& \text { S1C: } \gamma_{1}=0, H=0, \\
& \text { S2A: } \theta_{1}=\theta_{2}=0, \gamma_{1}=1, \\
& \text { S2B: } \theta_{2}=0, \gamma_{1}=1, \\
& \text { S2C: } \gamma_{1}=1,
\end{aligned}
$$

The estimated parameters (and fits) associated with the above specifications are provided in Table $1 .^{16}$

\section{Insert Table 1 here}

The results in Table 1 provide clear evidence that mispricing is affected by the fact that reported Amsterdam prices were spot prices prior to 1747 and time prices from 1747 onwards. This is evinced by the positive coefficient on the $\mathrm{SET}_{t} \times \mathrm{D} 47_{t}$ variable. These results are consistent with those in Beach et al. (2013). The inclusion of the stochastic trend significantly improves the fit of the model, with S2B providing the best fit to the data according to the Akaike information criterion (AIC). The results in Table 1 also indicate that the residuals from each model are stationary when the S1C, S2A, S2B and S2C specifications are used. ${ }^{17}$ This result confirms that (logged) Amsterdam and London prices are cointegrated as imposing the cointegrating vector $\boldsymbol{\beta}=[1,-1]^{\prime}$ delivers a stationary series once institutional effects have been taken into account.

The nature of the stochastic trend can be seen in Figure 2, which provides plots of the unadjusted and adjusted mispricing along with the stochastic trend. The plots demonstrate that this trend occasionally takes on large positive values for extended periods.

\section{Insert Figure 2 here}

As an alternative to the above models, one can also remove the maturity effects associated with time prices reported in Amsterdam after 1747 using a deterministic approach based on the cost of carry model. Specifically, reported (logged) prices in Amsterdam are given by

$$
y_{1, t}^{f}=y_{1, t}+\left(\mathrm{SET}_{t} \times \mathrm{D} 47_{t} \times \mathrm{INT}_{t}\right),
$$

\footnotetext{
16 This system is estimated via the Kalman filter technique using the state-space object in Eviews 8.0 (x64).

17 We use the Kwiatkowski-Phillips-Schmidt-Shin (KPSS) test statistic to examine the null hypothesis of stationary residuals.
} 
where $y_{1, t}$ denotes the effective (logged) spot price in Amsterdam, and $\mathrm{INT}_{t}$ is the risk-free interest rate (expressed on a daily basis). Rearranging (6) we are able to calculate $y_{1, t}$ and use this as the Amsterdam price in the calculation of mispricing.

To implement (6) we require the prevailing yield on government debt in Amsterdam during the eighteenth century. This represents a challenge as Homer and Sylla (2005) note: "the record of Dutch interest rates in the eighteenth century remains imprecise". However, they do state that interest rates were low and remained between $2 \%$ and $3 \%$ over much of the century. Given this we consider three constant interest rates of $2 \%, 2.5 \%$ and $3 \%$. Use of these rates results in three mispricing model specifications, which we refer to as the S3A, S3B and S3C specifications, respectively.

\subsection{The Estimated VEC Model}

A number of versions of the VEC model given by (1) are estimated. To illustrate, we consider lag lengths of one, two, three and four - that is, $p \in\{1,2,3,4\}$, and use the S2C adjusted mispricing series. ${ }^{18}$ The estimated parameters (and fits) are provided in Table $2 .{ }^{19}$

\section{Insert Table 2 here}

The results demonstrate that past mispricing has the expected effect on future returns in London and Amsterdam. Although our parameter estimates show slight differences to those of Dempster et al. (2000), they yield broadly the same patterns. Moreover, the sign of the adjustment coefficients $\left(\alpha_{1}\right.$ and $\left.\alpha_{2}\right)$ indicate that when the Amsterdam price is higher than the London price (i.e., mispricing is positive), next period returns in Amsterdam and London are significantly negative and positive, respectively. Moreover, the absolute values of these coefficients demonstrate that prices in Amsterdam are more sensitive to past mispricing - implying that London prices are more likely to Granger-cause Amsterdam prices in the long run.

\subsection{Estimated Price Discovery}

Price discovery measures are estimated using VEC models that include mispricing adjusted using each of the specifications described above (that is, S1A to S3C), with lag length determined by the AIC. However, as the results are fairly robust over the mispricing equation specifications we will focus our description of the results on those associated with $\mathrm{S} 2 \mathrm{C}$ mispricing. The results of the full sample analysis in Table 3 show that the London market significantly dominates for both stocks. For instance, the estimated London information (component) shares are $61.8 \%(85.0 \%)$ and $57.0 \%$ (74.8\%), for BOE and EIC stock respectively. Moreover, the component and information shares are significantly above $1 / 2$ (based on the bootstrap confidence intervals). Thus, it would appear that hypothesis 1 can be rejected.

\section{Insert Table 3 here}

The results pertaining to the determinants of the time-variation in component and information shares (sub-period analysis) appear fairly clear cut. First, there is evidence that these shares vary in a systematic fashion between peacetime and wartime (with dates adopted following Neal, 1987). ${ }^{20}$ For instance, the estimated London information (component) shares during peacetime are 65.0\% (91.0\%) and 58.1\% (79.1\%), while the estimated London information (component) shares during wartime are universally lower at $53.9 \%$ (62.4\%) and 53.2\% (59.1\%), for BOE and EIC stock, respectively. Moreover, these shares are significantly above $1 / 2$ during peacetime, but insignificantly different from $1 / 2$ during wartime - a finding consistent with the notion that war-related news from the continent may reach Amsterdam before London.

Price discovery also appears to be affected by institutional effects. In particular, the introduction of the Barnard Act has a downward impact on the London information shares for both stocks. ${ }^{21}$ Thus, this

\footnotetext{
18 The effect of this choice of mispricing model specification on the subsequent price discovery measures is examined later in the paper.

19 The VEC model is estimated via ordinary least squares in Eviews 8.0 (x64).

20 Neal's peace and war periods are 09/08/23 - 19/10/39, 11/11/48 - 14/07/56, 18/02/63 - 04/03/78, 06/12/82 $22 / 09 / 90$, and 21/10/39 - 23/10/48, 04/08/56 - 05/02/63, 02/03/78 - 20/11/82, 08/10/90 - 19/12/94, respectively. It should be noted that for the American War of Independence, it is arguable that a longer period could be considered, i.e. 1775-1783.

21 We follow Neal (1987) and use the 1723-1737 and 1738-1794 pre- and post-Barnard act samples, respectively.
} 
act which curtailed (low cost) forward-type trading of stocks, may have been responsible for a change in the amount of relative price discovery from London to Amsterdam. Similarly, when we consider the 1747 structural break in which reported Amsterdam prices changed from spot to time prices (Beach et al., 2013), a similar result holds. However, it is difficult to disentangle the effects of these changes on the data. Indeed, the accession of George III in 1760 also coincides with a reduction in the London component and information shares (results available on request). ${ }^{22}$

To further examine the time-varying nature of relative price discovery in each market, component and information shares are calculated using a 10-year rolling window of data (with each new estimation of the model occurring once a year) and S2C mispricing. ${ }^{23}$ The results in Figure 3 show that London tends to be the dominant market with component and information shares above $1 / 2$ for both stocks for long periods. However, the component and information shares vary considerably over the period, with large and statistically significant swings in the amount of price discovery in each market. There is also some evidence that when the information share measures are used there appears to be a decline in the amount of price discovery taking place in London. These results collectively indicate that one can reject hypothesis 2 for both stocks.

\section{Insert Figure 3 here}

\subsection{Data Irregularity Effects}

Neal (1987) documents variation in the time between the Amsterdam prices reported in the Amsterdamsche Courant. For the majority of observations, the number of days between reported prices is 14 days (coinciding with a bi-weekly data frequency). However, there is variation in the regularity of observations (over 50 days between observations are possible), with the wartime and peacetime periods appearing to differ in this regard (see Table 3 in Neal, 1987, for evidence). Consequently, it is possible that the results reported in Table 3 of the current paper may be biased.

To address the above issue we repeat our price discovery calculations using only regularly spaced observations. ${ }^{24}$ The results in Table 4 provide concrete evidence that data irregularly does not alter the main conclusions of the paper: London remains the dominant market, particularly during period of peace, with its importance declining over time.

\section{Insert Table 4 here}

\section{Conclusions}

This paper has employed a VEC model together with a component and information shares approach to investigate the relative price discovery roles of London and Amsterdam for two important stocks that were cross-listed across the two markets in the eighteenth century. The VEC model estimates show that the speed of adjustment back towards equilibrium is fast, with a sizeable proportion of any correction occurring within one period. The only sources of information in Amsterdam were the mail packet boats, which sailed at best twice per week and sometimes with considerable delay due to a lack of wind or wind from the wrong direction. ${ }^{25}$ Hence, given the physical impediments to information exchange between London and Amsterdam, we find that adjustments back to equilibrium worked remarkably quickly such that any possibilities for arbitrage would have disappeared within a few weeks.

To some extent in contrast with Dempster et al. (2000), we are able to show that Amsterdam had an important and increasing share in the price discovery of the markets over time, although the role of London was still greater throughout the sample period. Following Neal's (1987) suggestion, we split the sample

\footnotetext{
22 However, we should also consider a panic in London beginning in April 1761 and mentioned by Neal (1990, p. 170). Charles Mackay placed the blame for this panic on two earthquakes and the fear of a third, which had been prophesised by "a crack-brained fellow called Bell" (Mackay, 1995, p. 224). Hence it may well be that this reduction in London price discovery may be unconnected to the succession of George III.

23 Thus we begin with the January 1723 to December 1732 sample, followed by the January 1724 to December 1733 sample, and so on. For each window we determine the optimal lag structure in the VEC model using the AIC.

24 We define regularly spaced observations as those with a time interval between reported prices of between 11 and 17 days. Consequently, the only variation in data frequency that is permitted in due to the occurrence of religious holidays and thus the data "reflect precisely irregularities in trading activity on the Effectenbeurs" (Neal, 1987, p. 105).

25 See Koudijs (2013) for a detailed discussion of flows between London and Amsterdam and how volatility is affected by the arrival of news.
} 
in various ways in order to investigate the impact that wars, and changes in regulatory regime (e.g., the Barnard Act), had on the relative importance of the two centres in the price discovery process, finding that both appear to have had an impact.

Our findings provide further evidence that markets do not require the availability of real-time electronic information or a highly developed regulatory framework in order to function effectively. We are able to show that the prices of these early examples of cross-listed stocks were able to incorporate information from both listing venues despite operating in a period of great political and economic turbulence.

Acknowledgements The authors are grateful to Gary Shea for kindly providing us with his data on the dividend payments for the companies. We are also grateful for useful comments on previous versions of this paper by the Founding Managing Editor, Claude Diebolt, and two anonymous referees.

\section{References}

Aitken M, Di Marco E, Harris F (2012) Price discovery efficiency and information impounding on NYSE Euronext Paris. SSRN Working Paper http://ssrn.com/abstract $=2029338$.

Beach B, Norman S, Wills D (2013) Time or spot? A revaluation of Amsterdam market data prior to 1747. Cliometrica 7: 61-85.

Bowen H (1989) Investment and empire in the later eighteenth century: East India stockholding, 1756-1791. Economic History Review 42: 186-206.

Booth G, So R, Tse Y (1999) Price discovery in the German equity index derivatives market. Journal of Futures Markets 19: 619-643.

Campbell B, Hendry S (2007) Price discovery in Canadian and U.S. 10-Year government bond markets. Bank of Canada Working Paper 2007-43.

Caporale G, Girardi A (2013) Price discovery and trade fragmentation in a multi-market environment: Evidence from the MTS system. Journal of Banking and Finance 37: 227-240.

Chan K, Menkveld A, Yang Z (2007) The informativeness of domestic and foreign investors' stock trades: Evidence from the perfectly segmented Chinese market. Journal of Financial Markets 10: 391-415.

Chakravarty S, Gulen H, Mayhew S (2004) Informed trading in stock and option markets. Journal of Finance 59: $1235-1257$.

Chu Q, Hsieh W, Tse Y (1999) Price discovery on the S\&P 500 index markets: An analysis of spot index, index futures and SPDRs. International Review of Financial Analysis 8: 21-34.

Dale R (2004) The first crash: Lessons from the South Sea Bubble. Princeton University Press, Princeton and Oxford.

Davison A, Hinkley D (1997) Bootstrap Methods and their Application. Cambridge Series in Statistical and Probabilistic Mathematics. Cambridge University Press, Cambridge.

Dempster G, Wells J, Wills D (2000) A common-features analysis of Amsterdam and London financial markets during the eighteenth century. Economic Inquiry 38: 19-33.

Harris F, McInish T, Wood R (2002) Security price adjustment across exchanges: An investigation of common factor components for Dow stocks. Journal of Financial Markets 5: 277-308.

Harrison P (1998) Similarities in the distribution of stock market price changes between the eighteenth and twentieth Centuries. Journal of Business 71: 55-79. 
Hasbrouck J (1995) One security, many markets: Determining the contributions to price discovery. Journal of Finance 50: 1175-1199.

Hoag C, Norman S (2013) Transatlantic capital market price discovery during a financial crisis. Bulletin of Economic Research 65: 1-9.

Homer S, Sylla R (2005) A History of Interest Rates (4th edition). Wiley, Chichester.

Huang R (2002) The quality of ECN and Nasdaq market maker quotes. Journal of Finance 57: 1285-1319.

Koudijs P (2013) The boats that did not sail: Evidence on the sources of asset price volatility from an 18th century natural experiment. NBER Working Paper No. 18831.

Lehmann B (2002) Some desiderata for the measurement of price discovery across markets. Journal of Financial Markets 5: 259-276.

Lütkepohl H (1991). Introduction to multiple time series analysis. Springer-Verlag, Berlin.

Mackay C (1995) Extraordinary popular delusions and the madness of crowds. Crown Publications, London.

Mammen E (1993) Bootstrap and wild bootstrap for high dimensional linear models. Annals of Statistics 21: $255-285$.

Mizrach B, Otsubo Y (2014) The market microstructure of the European climate exchange. Journal of Banking and Finance 39: 107-116.

Neal L (1985) Integration of international capital markets: Quantitative evidence from the eighteenth to twentieth centuries. Journal of Economic History 45: 219-226.

Neal L (1987) The integration and efficiency of the London and Amsterdam stock markets in the Eighteenth century. Journal of Economic History 47: 97-115.

Neal L (1990) The rise of financial capitalism. Cambridge University Press, New York.

Pascual R, Pascual-Fuster B, Climent F (2006) Cross-listing, price discovery and the informativeness of the trading process. Journal of Financial Markets 9: 144-161.

Pesaran H, Shin Y (1996) Cointegration and speed of convergence to equilibrium. Journal of Econometrics 71: $117-43$.

Pesaran H, Shin Y (1998) Generalized impulse response analysis in linear multivariate models. Economic Letters 58: 17-29.

Shea, G. (2000). The course of the exchange: Measuring and interpreting returns processes in 18th and early 19th century Britain. Mimeo, Department of Economics, University of St. Andrews.

Stock J, Watson M (1988) Testing for common trends. Journal of the American Statistical Association 83: 1097-1107.

Van Dillen JG (1931) Effectenkoersen aan de Amsterdamsche Beurs, 1723-1794. Economische Historische Jaarboek 17: 1-46.

Wilson C (1941) Anglo-Dutch commerce and finance in the eighteenth century. Cambridge University Press, Cambridge.

Wright J (1999) British government borrowing in wartime, 1750-1815. Economic History Review 52: 355361. 
Yan B, Zivot E (2010) A structural analysis of price discovery measures. Journal of Financial Markets 13: $1-19$. 


\section{Appendices}

\section{A Bootstrap Procedure}

The wild bootstrap used in this paper consists of the following steps:

Step 1: Estimate the VEC model based on the original data to obtain the following vector of fitted return values

$$
\Delta \widehat{\mathbf{y}}_{t}=\widehat{\boldsymbol{\alpha}} \boldsymbol{\beta}^{\prime} \mathbf{y}_{t-1}+\sum_{i=1}^{p} \widehat{\boldsymbol{\Gamma}}_{i} \Delta \mathbf{y}_{t-i}
$$

with residuals given by $\widehat{\boldsymbol{\epsilon}}_{t}$. The estimation of this model can be based on the full sample, a sub-sample, or a rolling window of data. In each case the lag length is determined by the AIC.

Step 2: Construct bootstrap residuals as follows

$$
\widetilde{\boldsymbol{\epsilon}}_{t}=\widetilde{u}_{t} \widehat{\boldsymbol{\epsilon}}_{t}
$$

where $\widetilde{u}_{t}$ is obtained using the two-point distribution proposed by Mammen (1993), that is

$$
\widetilde{u}_{t}= \begin{cases}-(\sqrt{5}-1) / 2, & \text { with probability } p=(\sqrt{5}+1) /(2 \sqrt{5}), \\ +(\sqrt{5}+1) / 2, & \text { with probability } 1-p\end{cases}
$$

Step 3: Construct the bootstrap data generating process (DGP) using the bootstrap residuals

$$
\Delta \widetilde{\mathbf{y}}_{t}=\Delta \widehat{\mathbf{y}}_{t}+\widetilde{\boldsymbol{\epsilon}}
$$

Step 4: Re-estimate the model using the bootstrap DGP and construct the component and information shares using the respective formulae given by (3a) and (3b), denoting these by $\widetilde{M}_{j}$ if a time-invariant version is required (achieved via estimation over the full sample), or by $\widetilde{M}_{j, t}$ if a time-varying version is required (achieved via sub-period or rolling window estimation).

Step 5: Repeat Steps 2 to 4 a total of 1000 times. 
Table 1 - Mispricing Model Estimates

\begin{tabular}{|c|c|c|c|c|c|c|}
\hline Parameter & SOA & $\mathrm{S} 1 \mathrm{~A}$ & $\mathrm{~S} 2 \mathrm{~A}$ & SOB & S1B & $\mathrm{S} 2 \mathrm{~B}$ \\
\hline \multicolumn{7}{|c|}{ Panel A: Bank of England } \\
\hline$\widehat{\theta}_{1} \times 10^{3}$ & & $\begin{array}{l}0.026^{* *} \\
(0.005)\end{array}$ & $\begin{array}{c}-0.002 \\
(0.005)\end{array}$ & & $\begin{array}{l}0.020^{* *} \\
(0.005)\end{array}$ & $\begin{array}{c}0.009 \\
(0.006)\end{array}$ \\
\hline$\widehat{\theta}_{2} \times 10^{3}$ & & & $\begin{array}{c}0.042^{* *} \\
(0.005)\end{array}$ & & & $\begin{array}{l}0.026^{* *} \\
(0.010)\end{array}$ \\
\hline $\ln \widehat{G}$ & $\begin{array}{c}-10.431^{* *} \\
(0.013)\end{array}$ & $\begin{array}{c}-10.443^{* *} \\
(0.013)\end{array}$ & $\begin{array}{c}-10.484^{* *} \\
(0.013)\end{array}$ & $\begin{array}{c}-10.484^{* *} \\
(0.015)\end{array}$ & $\begin{array}{c}-10.492^{* *} \\
(0.014)\end{array}$ & $\begin{array}{c}-10.525^{* *} \\
(0.014)\end{array}$ \\
\hline $\ln \widehat{H}$ & & & & $\begin{array}{c}-17.143^{* *} \\
(0.381)\end{array}$ & $\begin{array}{c}-17.365^{* *} \\
(0.404)\end{array}$ & $\begin{array}{c}-17.100^{* *} \\
(0.363)\end{array}$ \\
\hline $\mathrm{SBC}$ & -7.577 & -7.589 & -7.625 & -7.623 & -7.634 & -7.635 \\
\hline KPSS Test Statistic & $2.029^{* *}$ & $1.984^{* *}$ & 0.319 & 0.008 & 0.009 & 0.007 \\
\hline \multicolumn{7}{|c|}{ Panel B: East India Company } \\
\hline$\widehat{\theta}_{1} \times 10^{3}$ & & $\begin{array}{c}-0.005 \\
(0.006)\end{array}$ & $\begin{array}{c}-0.045^{* *} \\
(0.006)\end{array}$ & & $\begin{array}{c}-0.005 \\
(0.006)\end{array}$ & $\begin{array}{c}-0.026^{* *} \\
(0.007)\end{array}$ \\
\hline$\widehat{\theta}_{2} \times 10^{3}$ & & & $\begin{array}{c}0.061^{* *} \\
(0.006)\end{array}$ & & & $\begin{array}{l}0.032^{* *} \\
(0.012)\end{array}$ \\
\hline $\ln \widehat{G}$ & $\begin{array}{c}-9.980^{* *} \\
(0.016)\end{array}$ & $\begin{array}{c}-9.981^{* *} \\
(0.017)\end{array}$ & $\begin{array}{c}-10.036^{* *} \\
(0.017)\end{array}$ & $\begin{array}{c}-10.080^{* *} \\
(0.017)\end{array}$ & $\begin{array}{c}-10.070^{* *} \\
(0.018)\end{array}$ & $\begin{array}{c}-10.083^{* *} \\
(0.018)\end{array}$ \\
\hline KPSS Test Statistic & $2.472^{* *}$ & $2.480^{* *}$ & 0.361 & 0.009 & 0.009 & 0.009 \\
\hline
\end{tabular}

Notes: This table provides parameter estimates associated with various specifications of the mispricing model using the full sample period, 09/08/1723 to 19/12/1794. Standard errors are given in parentheses. Also included are the log likelihood (LL), the Akaike information criterion (AIC) value, and the Schwarz Bayesian criterion (SBC) value. The Kwiatkowski-Phillips-Schmidt-Shin (KPSS) test statistic associated with the null hypothesis that the residuals are stationary is provided. Statistically significant coefficients are denoted by ${ }^{* *}(1 \%$ significance), and * $(5 \%$ significance). 
Table 2 - VEC Model Estimates

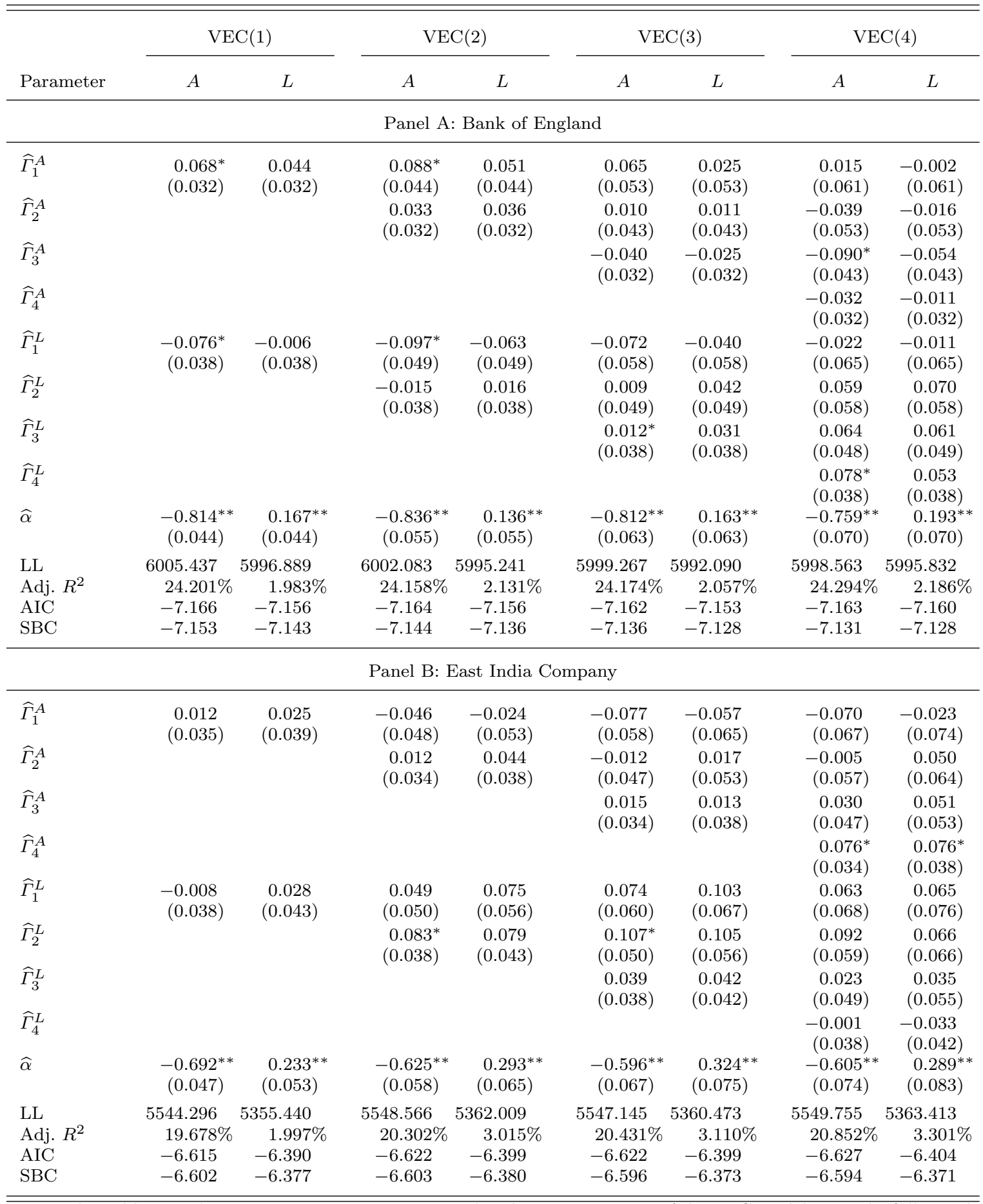

Notes: This table provides parameter estimates associated with various versions of the VEC model using the full sample period, 09/08/1723 to 19/12/1794. The mispricing series used in the VEC model is adjusted using the S2B mispricing model specification. The results associated with the Amsterdam market are given in the $A$ column, while the London results are given in the $L$ column. Coefficients on past Amsterdam returns have an $A$ superscript, and coefficients on past London returns have an $L$ superscript. Also included are the log likelihood (LL) value, the adjusted $R^{2}$ statistic, the Akaike information criterion (AIC) value, and the Schwarz Bayesian criterion (SBC) value. Statistically significant coefficients or test statistics are denoted by ${ }^{* *}(1 \%$ significance $)$, and * (5\% significance). 
Table 3 - London Component and Information Shares

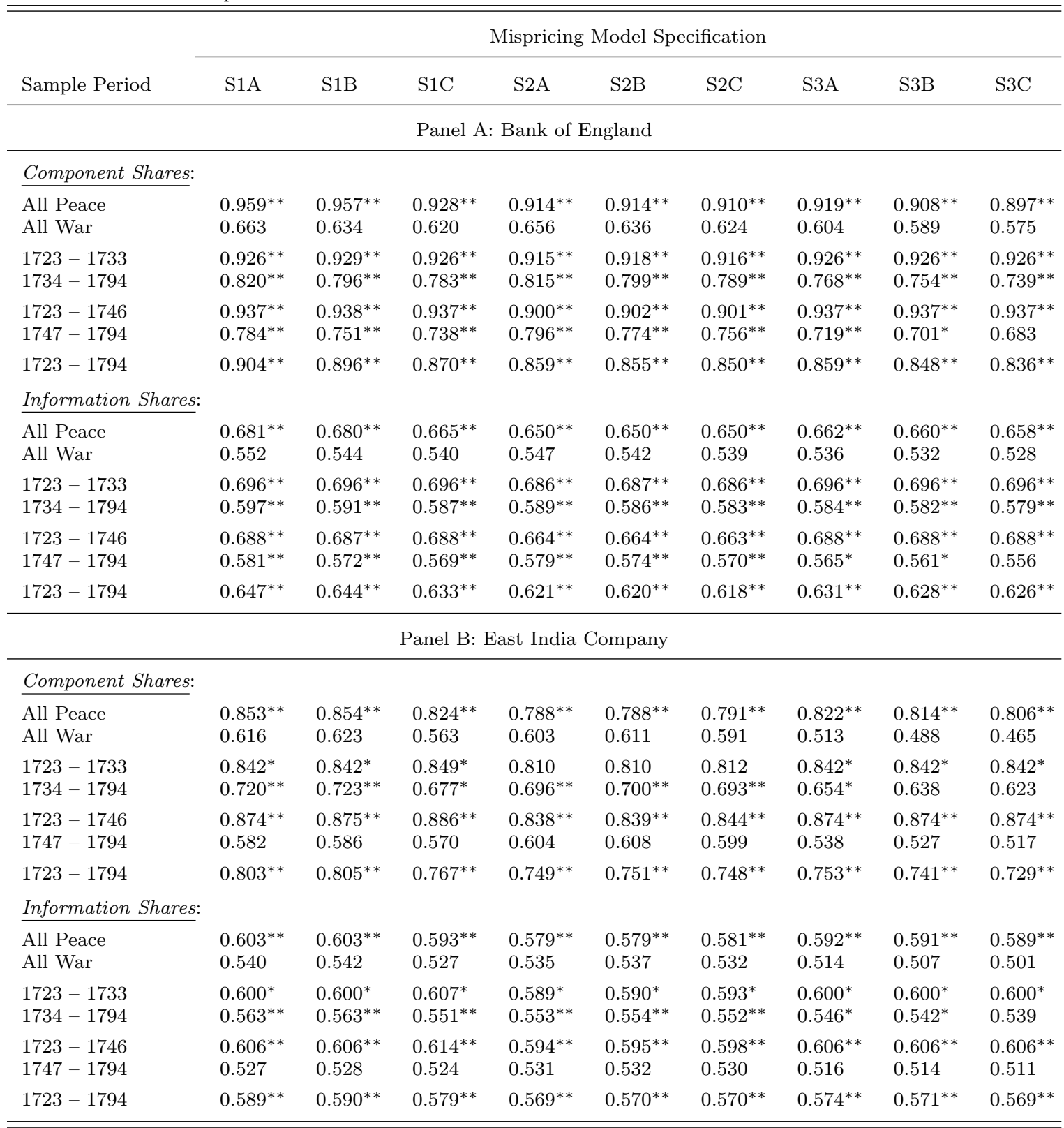

Notes: This table provides the estimated London component and information shares based on the VEC model with lag length determined by the AIC. The mispricing series used in the VEC model is adjusted using the S1A, S1B, S1C, S2A, $\mathrm{S} 2 \mathrm{~B}, \mathrm{~S} 2 \mathrm{C}, \mathrm{S} 3 \mathrm{~A}, \mathrm{~S} 3 \mathrm{~B}$ and S3C mispricing model specifications. The component and information shares are provided over various sub-periods. The null hypothesis is that the London component or information share equals $1 / 2$, and is tested using basic bootstrap confidence limits. The breakpoints are pre-determined. 
Table 4 - London Component and Information Shares (regularly observed data only)

\begin{tabular}{|c|c|c|c|c|c|c|c|c|c|}
\hline \multirow[b]{2}{*}{ Sample Period } & \multicolumn{9}{|c|}{ Mispricing Model Specification } \\
\hline & S1A & S1B & $\mathrm{S} 1 \mathrm{C}$ & $\mathrm{S} 2 \mathrm{~A}$ & $\mathrm{~S} 2 \mathrm{~B}$ & $\mathrm{~S} 2 \mathrm{C}$ & S3A & S3B & $\mathrm{S} 3 \mathrm{C}$ \\
\hline \multicolumn{10}{|c|}{ Panel A: Bank of England } \\
\hline \multicolumn{10}{|c|}{ Component Shares: } \\
\hline All Peace & $0.969^{* *}$ & $0.969^{* *}$ & $0.941^{* *}$ & $0.908^{* *}$ & $0.910^{* *}$ & $0.912^{* *}$ & $0.933^{* *}$ & $0.924^{* *}$ & $0.914^{* *}$ \\
\hline All War & 0.677 & 0.644 & 0.674 & 0.679 & 0.655 & 0.648 & 0.669 & 0.667 & 0.666 \\
\hline $1723-1733$ & $0.991^{* *}$ & $0.989^{* *}$ & $0.991^{* *}$ & $0.963^{* *}$ & $0.964^{* *}$ & $0.962^{* *}$ & $0.991^{* *}$ & $0.991^{* *}$ & $0.991^{* *}$ \\
\hline $1734-1794$ & $0.801^{* *}$ & $0.783^{* *}$ & $0.780^{* *}$ & $0.783^{* *}$ & $0.771^{* *}$ & $0.770^{* *}$ & $0.771^{* *}$ & $0.763^{* *}$ & $0.754^{* *}$ \\
\hline $1723-1746$ & $0.985^{* *}$ & $0.991^{* *}$ & $0.985^{* *}$ & $0.953^{* *}$ & $0.951^{* *}$ & $0.952^{* *}$ & $0.985^{* *}$ & $0.985^{* *}$ & $0.985^{* *}$ \\
\hline $1747-1794$ & $0.714^{* *}$ & $0.695^{*}$ & $0.684^{*}$ & $0.725^{* *}$ & $0.713^{* *}$ & $0.702^{* *}$ & $0.672^{*}$ & 0.661 & 0.650 \\
\hline $1723-1794$ & $0.924^{* *}$ & $0.918^{* *}$ & $0.902^{* *}$ & $0.866^{* *}$ & $0.864^{* *}$ & $0.863^{* *}$ & $0.894^{* *}$ & $0.886^{* *}$ & $0.879^{* *}$ \\
\hline \multicolumn{10}{|c|}{ Information Shares: } \\
\hline All Peace & $0.693^{* *}$ & $0.694^{* *}$ & $0.679^{* *}$ & $0.653^{* *}$ & $0.655^{* *}$ & $0.657^{* *}$ & $0.677^{* *}$ & $0.675^{* *}$ & $0.674^{* *}$ \\
\hline All War & 0.577 & 0.564 & 0.575 & 0.573 & 0.565 & 0.562 & 0.574 & 0.574 & 0.575 \\
\hline $1723-1733$ & $0.697^{* *}$ & $0.693^{* *}$ & $0.697^{* *}$ & $0.682^{* *}$ & $0.681^{* *}$ & $0.681^{* *}$ & $0.697^{* *}$ & $0.697^{* *}$ & $0.697^{* *}$ \\
\hline $1734-1794$ & $0.620^{* *}$ & $0.613^{* *}$ & $0.613^{* *}$ & $0.605^{* *}$ & $0.602^{* *}$ & $0.602^{* *}$ & $0.611^{* *}$ & $0.610^{* *}$ & $0.609^{* *}$ \\
\hline $1723-1746$ & $0.698^{* *}$ & $0.694^{* *}$ & $0.698^{* *}$ & $0.667^{* *}$ & $0.665^{* *}$ & $0.666^{* *}$ & $0.698^{* *}$ & $0.698^{* *}$ & $0.698^{* *}$ \\
\hline $1747-1794$ & $0.587^{* *}$ & $0.579^{*}$ & $0.576^{*}$ & $0.586^{* *}$ & $0.582^{* *}$ & $0.579^{* *}$ & $0.572^{*}$ & 0.568 & 0.564 \\
\hline $1723-1794$ & $0.673^{* *}$ & $0.670^{* *}$ & $0.662^{* *}$ & $0.637^{* *}$ & $0.637^{* *}$ & $0.638^{* *}$ & $0.660^{* *}$ & $0.659^{* *}$ & $0.659^{* *}$ \\
\hline \multicolumn{10}{|c|}{ Panel B: East India Company } \\
\hline \multicolumn{10}{|c|}{ Component Shares: } \\
\hline All Peace & $0.957^{* *}$ & $0.958^{* *}$ & $0.935^{* *}$ & $0.867^{* *}$ & $0.868^{* *}$ & $0.879^{* *}$ & $0.926^{* *}$ & $0.919^{* *}$ & $0.911^{* *}$ \\
\hline All War & 0.720 & 0.723 & 0.713 & 0.708 & 0.712 & 0.704 & 0.684 & 0.675 & 0.666 \\
\hline $1723-1733$ & $0.980^{* *}$ & $0.983^{* *}$ & $0.988^{* *}$ & $0.929^{* *}$ & $0.932^{* *}$ & $0.946^{* *}$ & $0.980^{* *}$ & $0.980^{* *}$ & $0.980^{* *}$ \\
\hline $1734-1794$ & $0.805^{* *}$ & $0.806^{* *}$ & $0.775^{* *}$ & $0.757^{* *}$ & $0.758^{* *}$ & $0.762^{* *}$ & $0.773^{* *}$ & $0.765^{* *}$ & $0.757^{* *}$ \\
\hline $1723-1746$ & $0.996^{* *}$ & $0.999^{* *}$ & $0.970^{* *}$ & $0.930^{* *}$ & $0.933^{* *}$ & $0.948^{* *}$ & $0.996^{* *}$ & $0.996^{* *}$ & $0.996^{* *}$ \\
\hline $1747-1794$ & 0.663 & 0.663 & 0.668 & $0.678^{*}$ & $0.678^{*}$ & $0.678^{*}$ & $0.668^{*}$ & 0.669 & 0.670 \\
\hline $1723-1794$ & $0.910^{* *}$ & $0.912^{* *}$ & $0.893^{* *}$ & $0.835^{* *}$ & $0.837^{* *}$ & $0.844^{* *}$ & $0.880^{* *}$ & $0.872^{* *}$ & $0.865^{* *}$ \\
\hline \multicolumn{10}{|c|}{ Information Shares: } \\
\hline All Peace & $0.657^{* *}$ & $0.658^{* *}$ & $0.648^{* *}$ & $0.616^{* *}$ & $0.617^{* *}$ & $0.623^{* *}$ & $0.644^{* *}$ & $0.642^{* *}$ & $0.641^{* *}$ \\
\hline All War & $0.573^{*}$ & $0.574^{*}$ & 0.574 & $0.567^{*}$ & $0.568^{*}$ & $0.567^{*}$ & 0.565 & 0.563 & 0.562 \\
\hline $1723-1733$ & $0.651^{* *}$ & $0.653^{* *}$ & $0.671^{* *}$ & $0.633^{* *}$ & $0.635^{* *}$ & $0.642^{* *}$ & $0.651^{* *}$ & $0.651^{* *}$ & $0.651^{* *}$ \\
\hline $1734-1794$ & $0.602^{* *}$ & $0.602^{* *}$ & $0.593^{* *}$ & $0.582^{* *}$ & $0.583^{* *}$ & $0.585^{* *}$ & $0.593^{* *}$ & $0.592^{* *}$ & $0.591^{* *}$ \\
\hline $1723-1746$ & $0.650^{* *}$ & $0.652^{* *}$ & $0.669^{* *}$ & $0.626^{* *}$ & $0.628^{* *}$ & $0.636^{* *}$ & $0.650^{* *}$ & $0.650^{* *}$ & $0.650^{* *}$ \\
\hline $1747-1794$ & $0.564^{*}$ & $0.564^{*}$ & $0.566^{*}$ & $0.566^{* *}$ & $0.566^{* *}$ & $0.566^{*}$ & $0.568^{*}$ & $0.569^{*}$ & $0.571^{*}$ \\
\hline $1723-1794$ & $0.639^{* *}$ & $0.640^{* *}$ & $0.633^{* *}$ & $0.606^{* *}$ & $0.606^{* *}$ & $0.610^{* *}$ & $0.627^{* *}$ & $0.626^{* *}$ & $0.625^{* *}$ \\
\hline
\end{tabular}

Notes: This table provides the estimated London component and information shares based on the VEC model with lag length determined by the AIC. The mispricing series used in the VEC model is adjusted using the S1A, S1B, S1C, S2A, S2B, S2C, S3A, S3B and S3C mispricing model specifications. The component and information shares are provided over various sub-periods, where only data with a frequency of between 11 and 17 days are considered. The null hypothesis is that the London component or information share equals $1 / 2$, and is tested using basic bootstrap confidence limits. The breakpoints are pre-determined. 
(a) BOE prices

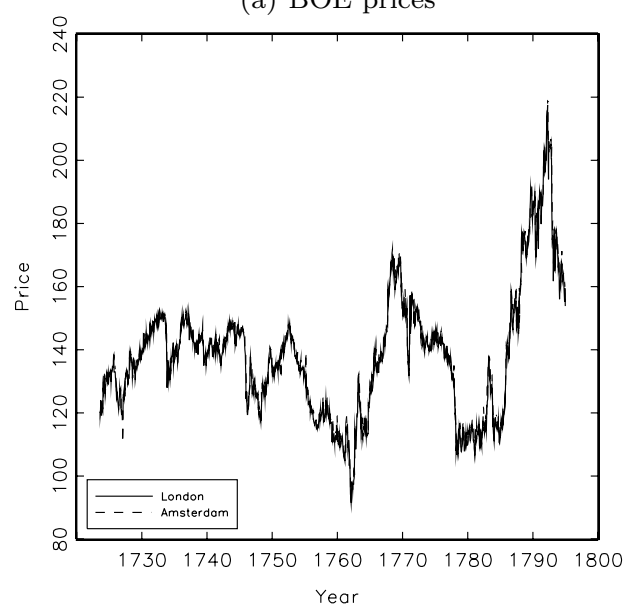

(c) BOE returns

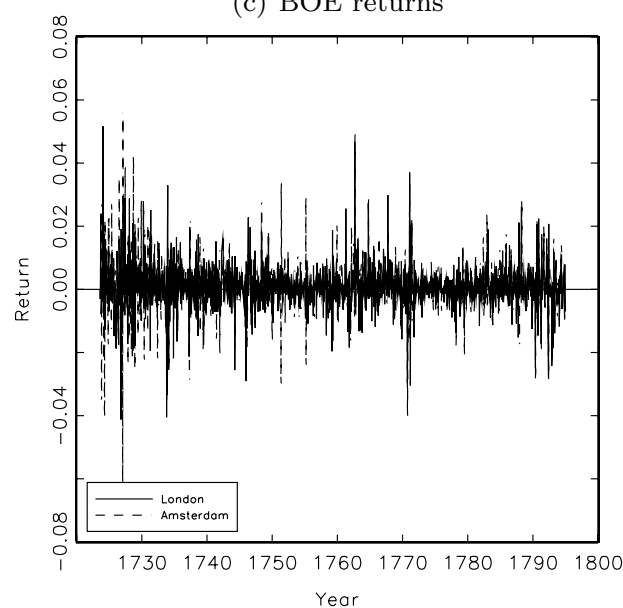

(b) EIC prices

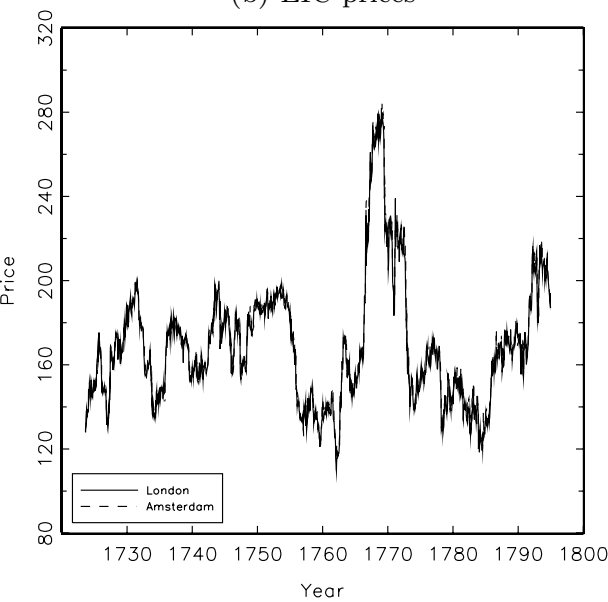

(d) EIC returns

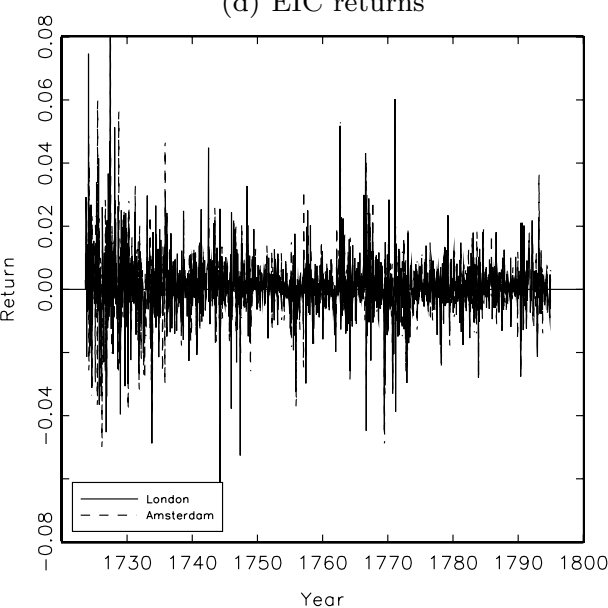

Fig. 1 - Prices and Returns

This figure plots the prices and log returns associated with Bank and England (BOE) and East India Company (EIC) stocks over the sample period, 09/08/1723 to 19/12/1794. 
(a) BOE (unadjusted mispricing)

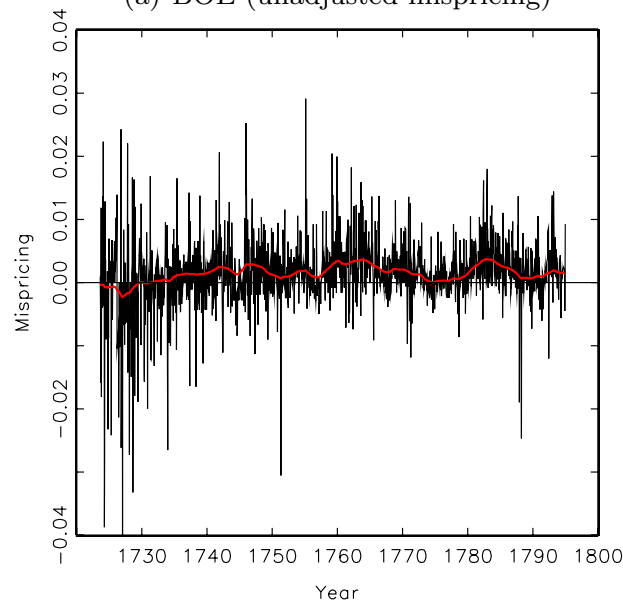

(c) BOE (adjusted mispricing)

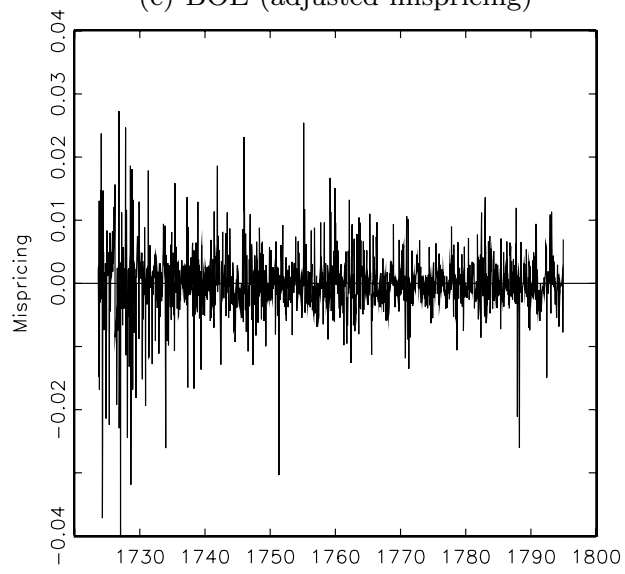

Year (b) EIC (unadjusted mispricing)

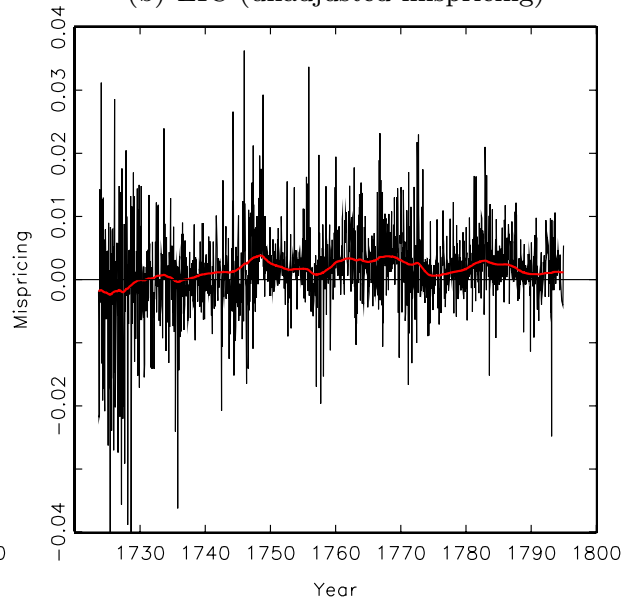

(d) EIC (adjusted mispricing)

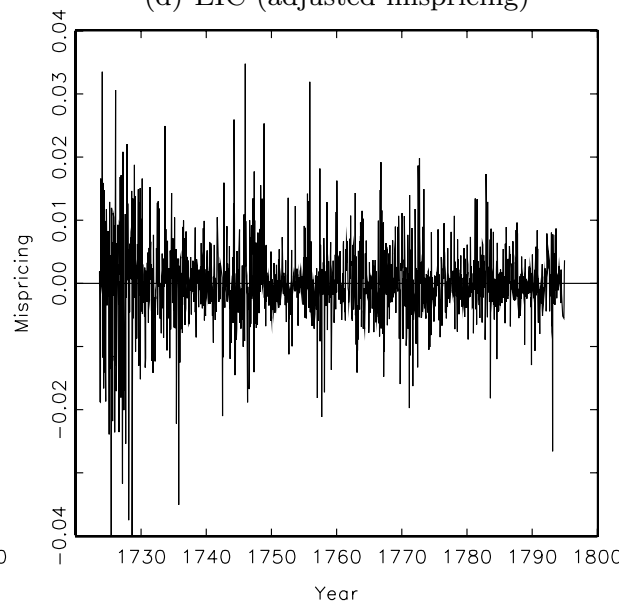

Fig. 2 - Mispricing

This figure plots the unadjusted and S2C-adjusted mispricing series associated with Bank and England (BOE) and East India Company (EIC) stocks over the sample period, 09/08/1723 to 19/12/1794. The red line in the unadjusted mispricing plot is the estimated stochastic trend. 
(a) Excess Component Share (BOE)

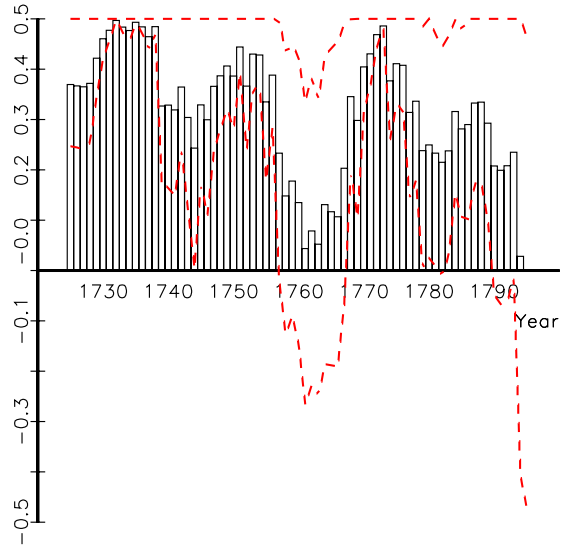

(c) Excess Information Share (BOE)

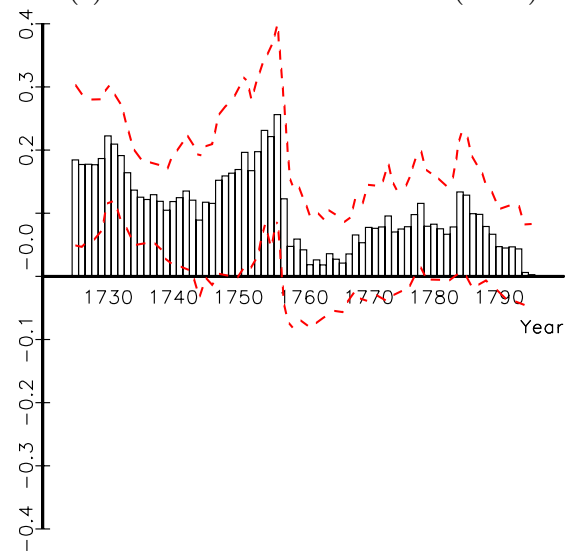

(b) Excess Component Share (EIC)

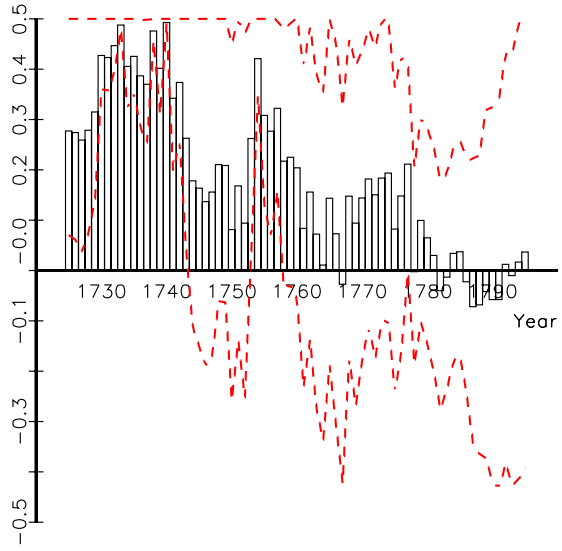

(d) Excess Information Share (EIC)

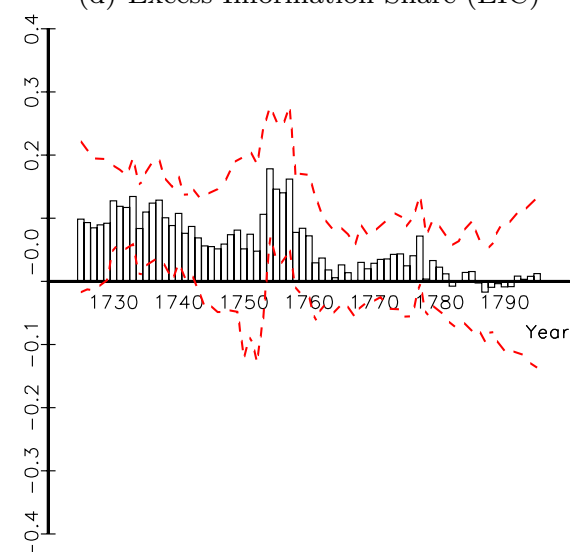

Fig. 3 - Time-varying London Information Shares

This figure plots the estimated London component/information shares minus $1 / 2$ (referred to as the excess component/information share) and the $2.5 \%$ and $97.5 \%$ bootstrap confidence interval limits, associated with Bank and England (BOE) and East India Company (EIC) stocks. These shares are calculated via the VEC model (with lag length determined by the AIC) estimated using a ten year rolling window of data. The mispricing series used in the VEC model is adjusted using the $\mathrm{S} 2 \mathrm{C}$ mispricing model specification. 